\title{
Hypoxic gene expression in chronic hepatitis $B$ virus infected patients is not observed in state-of-the-art in vitro and mouse infection models
}

\author{
Peter Jianrui Liu' ${ }^{1,7}$, James M. Harris ${ }^{1,7}$, Emanuele Marchi' ${ }^{2}$, Valentina D'Arienzo ${ }^{1}$, \\ Thomas Michler ${ }^{3}$, Peter A. C. Wing ${ }^{1}$, Andrea Magri ${ }^{1}$, Anna Maria Ortega-Prieto ${ }^{4}$, \\ Maarten van de Klundert ${ }^{3}$, Jochen Wettengel ${ }^{3}$, David Durantel ${ }^{5}$, Marcus Dorner ${ }^{4,8}$, \\ Paul Klenerman ${ }^{2}$, Ulrike Protzer ${ }^{3}$, Efstathios S. Giotis ${ }^{4,6}$ \& Jane A. McKeating ${ }^{1 \times}$
}

Hepatitis B virus (HBV) is the leading cause of hepatocellular carcinoma (HCC) worldwide. The prolyl hydroxylase domain (PHD)-hypoxia inducible factor (HIF) pathway is a key mammalian oxygen sensing pathway and is frequently perturbed by pathological states including infection and inflammation. We discovered a significant upregulation of hypoxia regulated gene transcripts in patients with chronic hepatitis B (CHB) in the absence of liver cirrhosis. We used state-of-the-art in vitro and in vivo HBV infection models to evaluate a role for $\mathrm{HBV}$ infection and the viral regulatory protein $\mathrm{HBx}$ to drive HIF-signalling. HBx had no significant impact on HIF expression or associated transcriptional activity under normoxic or hypoxic conditions. Furthermore, we found no evidence of hypoxia gene expression in HBV de novo infection, $\mathrm{HBV}$ infected human liver chimeric mice or transgenic mice with integrated HBV genome. Collectively, our data show clear evidence of hypoxia gene induction in CHB that is not recapitulated in existing models for acute HBV infection, suggesting a role for inflammatory mediators in promoting hypoxia gene expression.

HBV is a global health problem with more than 250 million people chronically infected and at least 780,000 deaths/year from HBV-related liver diseases such as liver cirrhosis and hepatocellular carcinoma (HCC) ${ }^{1,2}$. HBV replicates in hepatocytes within the liver and current anti-viral treatments suppress viral replication but are not curative, largely due to the persistence of the viral covalently closed circular DNA (cccDNA) reservoir ${ }^{3}$. Chronic hepatitis $\mathrm{B}(\mathrm{CHB})$ is a virus-associated, inflammatory liver disease and one of the leading causes of $\mathrm{HCC}^{4}$, one of the fastest rising and fourth most common cause of cancer related-death world-wide ${ }^{5}$. Curative therapies (tumour ablation, resection or liver transplantation) are dependent on early detection, however, the majority of HBV and non-viral associated HCC cases are diagnosed at a late stage often resulting in a poor prognosis ${ }^{6}$. Despite significant advances in our understanding of the HBV replicative life cycle, the mechanisms underlying HCC pathogenesis are not well defined ${ }^{7}$.

Although liver cirrhosis is a major risk factor for developing HCC, 10-20\% of HBV infected patients that develop HCC are non-cirrhotic, highlighting a role for HBV to promote carcinogenesis via direct and indirect inflammatory mechanisms ${ }^{7}$. Three major and non-exclusive viral-dependent pathways have been proposed: (i) integration of viral DNA into the host genome; (ii) expression of viral oncogenic proteins and (iii) viral-driven changes in host gene transcription (reviewed in ${ }^{8}$ ). The viral encoded regulatory hepatitis B X protein $(\mathrm{HBx})$ has been reported to promote the expression of both viral and selected host genes, where a recent study reported

\footnotetext{
${ }^{1}$ Nuffield Department of Medicine Research Building, University of Oxford, Oxford OX3 7LF, UK. ${ }^{2}$ Medawar Building, University of Oxford, South Parks Road, Oxford OX1 3SY, UK. ${ }^{3}$ Institute of Virology, Technical University of Munich/Helmholtz Zentrum München, Trogerstrasse 30, 81675 Munich, Germany. ${ }^{4}$ Section of Molecular Virology, Department of Infectious Diseases, Imperial College London, London W2 1PG, UK. ${ }^{5}$ Cancer Research Center of Lyon (CRCL), INSERM U1052, and University of Lyon (UCBL1), Lyon, France. ${ }^{6}$ School of Life Sciences, University of Essex, Colchester C04 3SQ, UK. ${ }^{7}$ These authors contributed equally: Peter Jianrui Liu and James M. Harris. ${ }^{8} \mathrm{M}$. Dorner is deceased. ${ }^{\square}$ email: jane.mckeating@ndm.ox.ac.uk
} 
HBx binding to $>5,000$ host genes with diverse roles in metabolism, chromatin maintenance and carcinogenesis ${ }^{9}$. There is clearly an urgent need to increase our understanding of HBV mediated carcinogenesis to support the development of tools to identify CHB patients at risk of HCC development.

The liver receives oxygenated blood from the hepatic artery and oxygen-depleted blood via the hepatic portal vein, resulting in an oxygen gradient of $4-8 \%$ across the pericentral and periportal areas, respectively ${ }^{10}$. This oxygen gradient has been reported to associate with liver zonation, a phenomenon where hepatocytes show distinct functional and structural heterogeneity across the parenchyma ${ }^{11,12}$. Recent single-cell RNA sequencing analysis of the mouse liver highlights a major role for hypoxic and Wnt signalling pathways to shape liver zonation profiles in the normal healthy liver with an enrichment of hypoxic gene expression in the pericentral area ${ }^{13}$. Importantly, this oxygen gradient is readily perturbed in pathological states such as infection, inflammation and cirrhosis $^{14}$. One of the best studied oxygen sensing mechanisms is the hypoxia inducible factor (HIF) pathway ${ }^{15}$. As HIF-signalling pathways are altered in many diseases, including cancer and inflammatory conditions, pharmacological approaches to modulate HIF activity offer promising therapeutic opportunities ${ }^{16,17}$. When oxygen is abundant, newly synthesised HIF a subunits, including HIF-1 $\alpha$ and HIF-2 $\alpha$ isomers, are rapidly hydroxylated by prolyl-hydroxylase domain (PHD) proteins and targeted for poly-ubiquitination and proteasomal degradation. In contrast when oxygen is limited these HIFa subunits translocate to the nucleus, dimerize with HIF- $\beta$ and positively regulate the transcription of a myriad of host genes involved in cell metabolism, proliferation, angiogenesis and immune regulation. Dai et al. reported that increased HIF-1a mRNA and protein expression in HCC are prognostic for more advanced disease stages and poor overall survival post-surgical tumour resection ${ }^{18}$. Furthermore, Xiang et al. and Zheng et al. showed that HIF-1a protein expression is predictive of HCC lymph node metastasis and vascular invasion ${ }^{19,20}$. Thus, HIF signalling could have an important role in progressive liver disease and HCC development ${ }^{14}$.

In addition to hypoxia, inflammation, oxidative stress and viral infection can promote HIF-transcriptional activity. The host inflammatory mediators nuclear factor- $\kappa \mathrm{B}(\mathrm{NF}-\kappa \mathrm{B})$ and tumor necrosis factor- $\alpha$ (TNF- $\alpha)$ induce HIF-1 $\alpha$ transcription ${ }^{21,22}$. Reactive oxygen species (ROS) produced by inflammatory cells provide a further mechanism for inflammation-driven HIF-signalling ${ }^{23-25}$. Several viruses induce the HIF signaling pathway including hepatitis $\mathrm{C}$ virus ${ }^{26-28}$, human papillomavirus ${ }^{29}$, Kaposi sarcoma-associated herpesvirus ${ }^{30}$ and human cytomegalovirus $^{31}$. Several reports have suggested that HBx can interact with and stabilize HIFs ${ }^{32-40}$, however, this proposed HBx-HIF interplay awaits validation in HBV replication in vitro and in vivo model systems.

In this study, we report a significant upregulation of hypoxic gene expression in a cohort of chronic HBV infected patients ${ }^{41}$. Our studies to investigate the underlying mechanism using state-of-the-art in vitro and in vivo HBV transgenic mice and human liver chimeric mice models show limited evidence of hypoxic gene expression. These studies highlight a major role of liver inflammation and a complex interplay between HBV and HIF signalling in the chronic infected liver that is not recapitulated by current infection-competent model systems. Collectively, our data show clear evidence of hypoxia-driven gene expression in $\mathrm{CHB}$ in the absence of cirrhosis or HCC development that may play a role in driving hepatocarcinogenesis.

\section{Results}

Increased hypoxia gene signature in chronic hepatitis B. To determine whether there is any association between hypoxic responsive transcription and CHB, we performed Gene Set Enrichment Analysis (GSEA) on microarray data from a cohort of chronic HBV infected patients $(n=90)$ that were free of cirrhosis or HCC and uninfected control subjects (healthy, $n=6$ ) ${ }^{41}$. We used a panel of 43 hypoxia gene signatures obtained from the Molecular Signatures Database (MSigDB v 7.0 $)^{42}$, that included hypoxia upregulated genes from diverse tissues and cancer types. We observed a significant enrichment $(\mathrm{FDR}<0.05)$ of 19 gene sets in the CHB cohort (Fig. 1a). Since hypoxic-transcriptional responses can vary between cell and tissue types ${ }^{43}$ and none of the MSigDB signatures were liver-derived (Supplementary Table 1), we analysed an RNA-sequencing (RNA-seq) transcriptome of human hepatoma derived HepG2 cells ${ }^{44}(0.5 \%$ oxygen for $16 \mathrm{~h})$. We identified 80 hypoxic upregulated genes (greater than twofold change, FDR <0.05) (Supplementary Table 2) and GSEA showed an enrichment $(\mathrm{FDR}=0.077)$ in the $\mathrm{CHB}$ cohort $($ Fig. $1 \mathrm{~b})$. To further validate these results, we analysed the acute transcriptional response of primary human hepatocytes $(\mathrm{PHHs})^{45}$ cultured under $1 \%$ oxygen for $4 \mathrm{~h}$ and identified 113 upregulated genes $(\mathrm{FC}>2$; FDR $<0.05)$ and GSEA showed an enrichment in CHB (Supplementary Fig. 2a). Since PHHs can rapidly de-differentiate and lose hepatocyte-specific function in vitro ${ }^{46,47}$, it was reassuring to observe an overlap of hypoxic regulated genes in HepG2 and PHHs (Supplementary Fig. 2b).

CHB reflects a dynamic interaction between virus infected hepatocytes and immune cells and periods of active hepatitis, as measured by the elevated activity of the liver enzyme alanine aminotransferase (ALT), associate with increased viremia ${ }^{48}$. Grouping our CHB cohort by ALT activity showed a significant enrichment $(\mathrm{FDR}=0.110)$ of the hypoxic HepG2 derived gene set in patients with elevated ALT $($ ALT $>40 \mathrm{IU} / \mathrm{mL})(\mathrm{n}=57)$ compared to those with normal ALT $(n=25)$ (Fig. 1c). To evaluate whether hypoxic gene expression is observed in other inflammatory liver disease we studied a cohort of hepatitis $\mathrm{C}$ virus (HCV) infected patients with cirrhosis $(n=41)^{49}$ and observed a significant enrichment of the hypoxic HepG2 gene signature (FDR $\left.=0.006\right)$ in the infected group compared to normal controls $(n=19)$ (Fig. 1d). Analysing the leading edge genes in the CHB $(\mathrm{n}=30)$ and $\mathrm{HCV}(\mathrm{n}=23)$ cohorts identified 10 common genes, however, the majority of genes $(57 \%)$ were unique to their respective cohorts.

We hypothesized that the hypoxic gene signature in $\mathrm{CHB}$ was mediated via inflammatory pathways. To evaluate this assumption we studied enriched pathways in the CHB liver using the hallmark gene sets from MSigDB. This analysis identified genes associated with allograft rejection as the most significantly upregulated gene set in CHB. Interestingly HIF-1a was one of the leading-edge genes in this subset; contributing significantly to the core enrichment score. We noted increased HIF-1a mRNA levels in the CHB patients compared to control subjects 


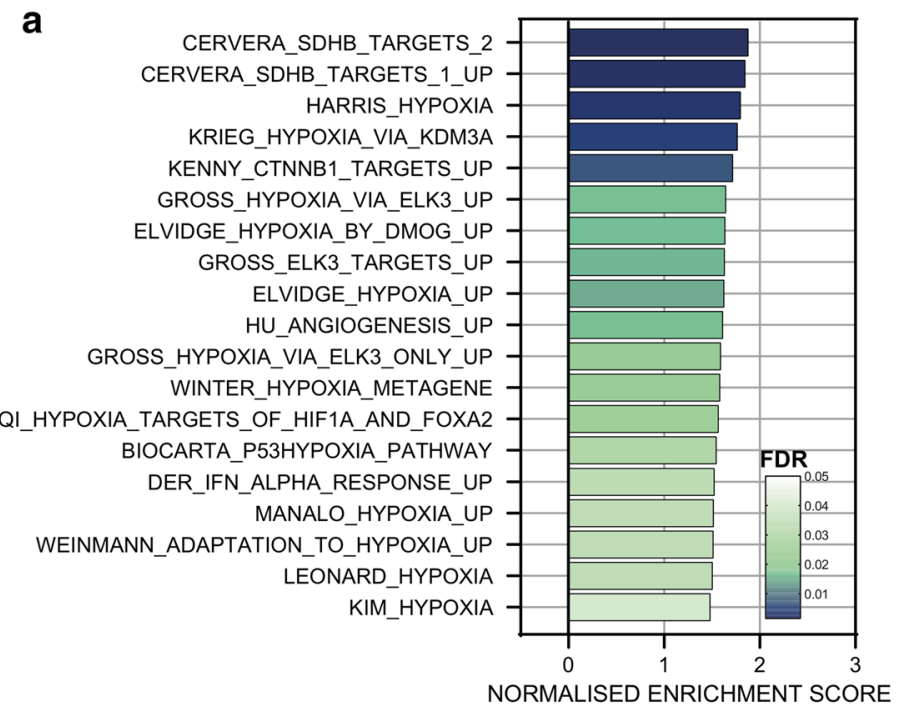

b

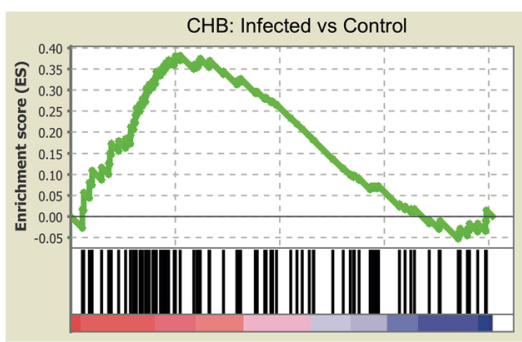

C

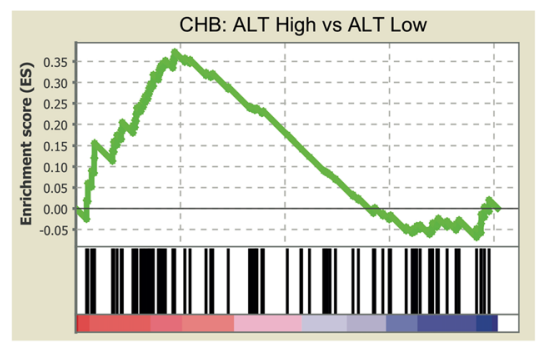

d

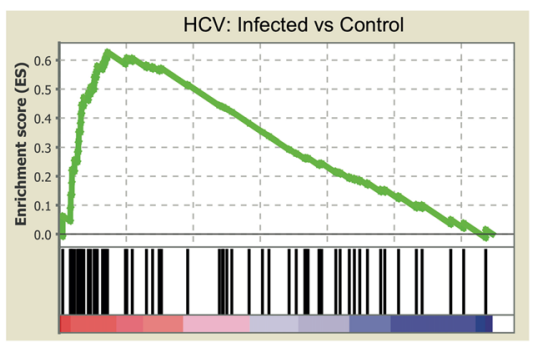

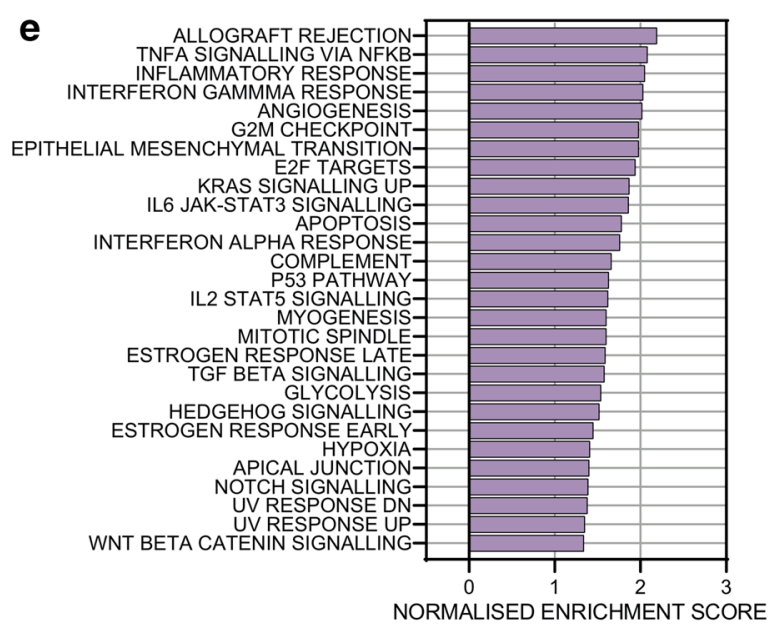

Figure 1. Increased hypoxia gene expression in CHB. Hypoxia upregulated gene signatures from Molecular Signatures Database were assessed in the $\mathrm{CHB}$ cohort, 19 significantly upregulated gene signatures identified $($ FDR $<0.05)$ and ranked by Normalized Enrichment Score (NES) (a). GSEA shows a significant enrichment of HepG2 defined hypoxic genes in CHB cohort (FDR =0.077). The gene set was based on Fold Change $>2$, and $\mathrm{FDR}<0.05 ; 80$ genes satisfied these criteria and are listed in Supplementary Table 2 (b). CHB cohort was grouped by peripheral ALT activity, with subjects $>40 \mathrm{IU} / \mathrm{L}(\mathrm{n}=57)$ or $<40 \mathrm{IU} / \mathrm{L}(\mathrm{n}=25)$. GSEA shows a significant enrichment of HepG2 defined hypoxic genes in patients with elevated ALT (FDR=0.110) (c). HepG2 hypoxic gene set was enriched $(\mathrm{FDR}=0.006)$ in $\mathrm{HCV}$ infected patients with cirrhosis $(\mathrm{n}=41)$ compared to normal liver controls $(n=19)(\mathbf{d})$. MSigDB hallmark gene sets identified the most upregulated pathways in the CHB cohort: 28 gene sets were significantly enriched $($ FDR $<0.05)$ and are ranked by NES $(\mathbf{e})$. All GSEA was performed using GSEA_4.0.3 $3^{71}$. 
a

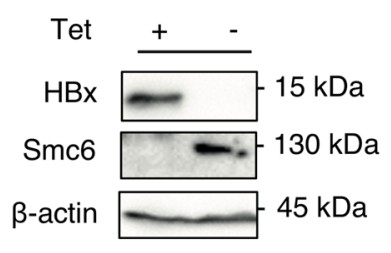

b

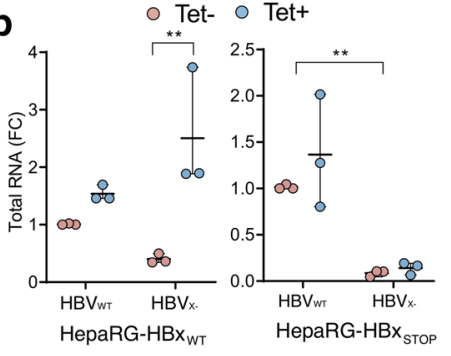

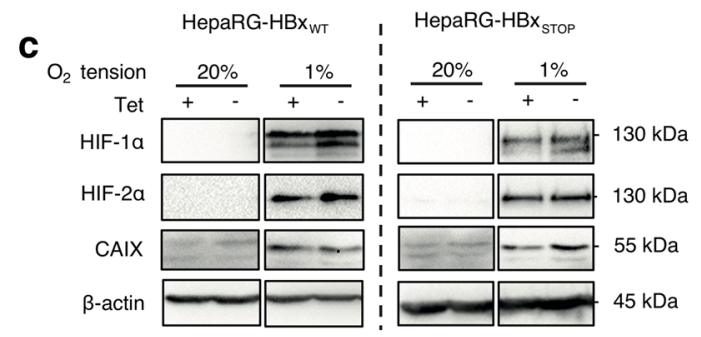

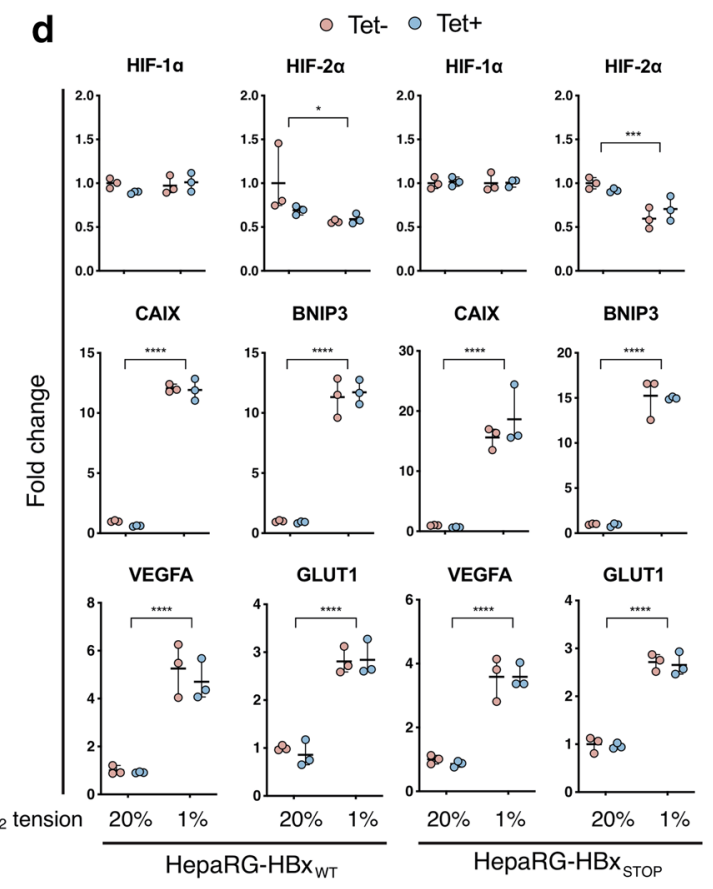

e

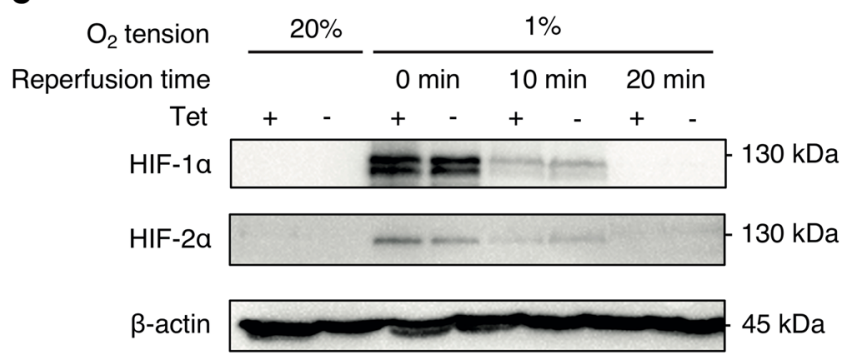

Figure 2. Effect of HBx on HIF expression and transcriptional activity in HepaRG cells. HepaRG cells encoding $\mathrm{HBx}$ were incubated with Tet $(50 \mu \mathrm{M})$ for $24 \mathrm{~h}$ and $\mathrm{HBx}$ protein and Smc6 expression detected by western blot, uncropped blots are available in Supplementary Fig. 2 (a). Differentiated HepaRG cells encoding WT or mutated $\mathrm{HBx}(\mathrm{STOP})$ were treated or not with tetracycline $(1 \mu \mathrm{M})$ and infected with $\mathrm{HBV}_{\mathrm{WT}}$ or $\mathrm{HBV}_{\mathrm{X}-}$ and 13 days later infection assessed by measuring total viral RNAs. The data is normalised for each cell line relative to $\mathrm{HBV}_{\mathrm{WT}}$ infection without Tet and represent the mean of 3 independent experiments; 2-way-ANOVA with Bonferroni correction was applied with $\mathrm{p}<0.05$ deemed as significant $(\mathbf{b})$. HepaRG cells encoding WT or mutated HBx (STOP) were incubated with or without Tet $(50 \mu \mathrm{M}, 24 \mathrm{~h})$ and cultured under $20 \%$ or $1 \%$ oxygen conditions for $24 \mathrm{~h}$. Cells were lysed and expression of HIF-1 $\alpha$, HIF-2 $\alpha$, Carbonic anhydrase IX (CAIX) and housekeeping gene B-actin assessed by western blotting, uncropped blots are available in Supplementary Figs. 3 and 4 (c) and mRNA levels of HIF-1 $\alpha$, HIF-2 $\alpha$ and several HIF target genes (CAIX, BNIP3, VEGFA and GLUT1) quantified by qPCR (d). HepaRG cells encoding wild type HBx were incubated with Tet $(50 \mu \mathrm{M}, 24 \mathrm{~h})$ and cultured at $20 \%$ or $1 \%$ oxygen for $24 \mathrm{~h}$. The hypoxic cultures were returned to $20 \%$ oxygen. After 10 or $20 \mathrm{~min}$, cells were lysed and screened for HIF-1 $\alpha$ or HIF- $2 \alpha$ and housekeeping gene $\beta$-actin expression by western blot, uncropped blots are available in Supplementary Fig. 5 (e). The data is shown from a single experiment and is representative of three independent experiments and represents mean \pm standard deviation. Normality distribution was assessed by D’Agostino-Pearson test; 2-way-ANOVA with Bonferroni correction was applied with $\mathrm{p}<0.05$ deemed as significant.

( $\log 2 \mathrm{FC}=2.648, \mathrm{p}=0.005)$. Moreover, we observed a significant increase in inflammatory signaling pathways in CHB liver: TNF- $\alpha$ signaling via NF- $\kappa B$ ', 'Inflammatory Response' and 'Interferon Gamma Response' (Fig. 1e). In summary these data support the conclusion that the hypoxic phenotype in the diseased liver is likely driven by local inflammation, rather than a direct result of viral infection.

Limited evidence for HBx to stabilise HIF-1 $\alpha$ or HIF-2 $\alpha$ expression or associated transcriptional activity in vitro. As HBx is the major viral encoded transcriptional activator, previously reported to stabilize $\mathrm{HIFs}^{32-40}$, we used the bipotent HepaRG cell line expressing $\mathrm{HBx}\left(\mathrm{HepaRG-HBx} \mathrm{WT}_{\text {T }}\right.$ ) under a tetracycline (Tet) inducible promoter ${ }^{50,51}$ to study HBx-HIF interplay. HBx promotes viral transcription by degrading the host structural maintenance of chromosomes (Smc) complex Smc5/6 ${ }^{52}$ and we confirmed that Tet induced HBx expression, loss of Smc6 expression (Fig. 2a) and restored replication of a defective HBV mutant lacking HBx 


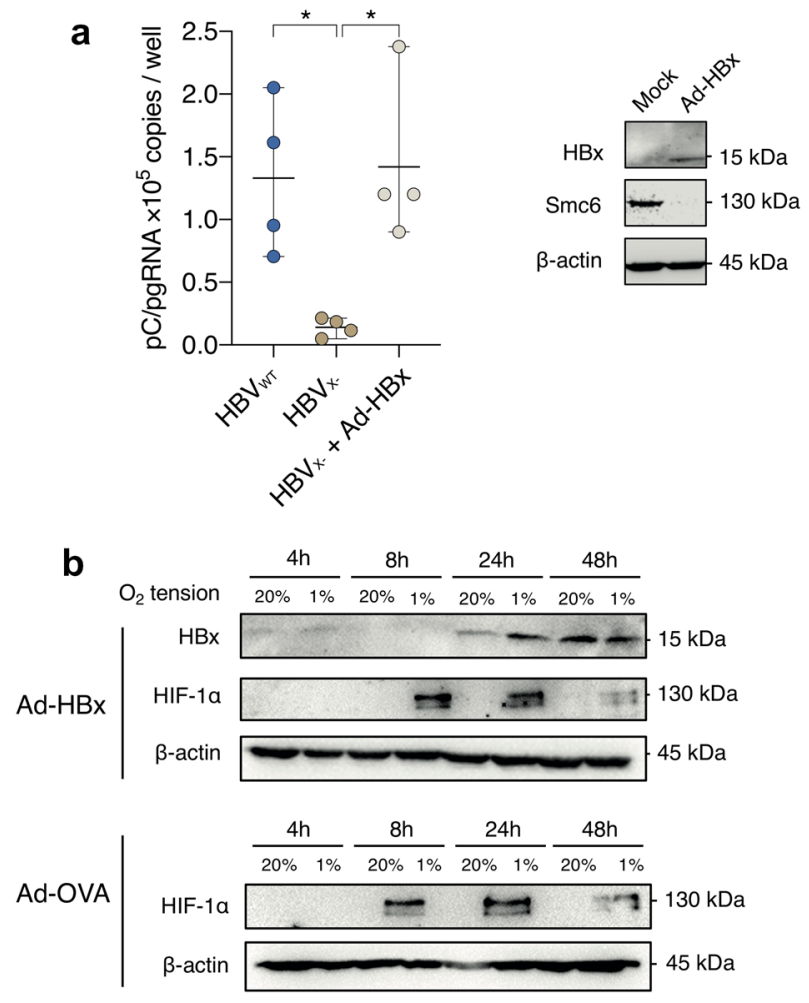

Figure 3. Effect of HBx expression on HIF expression and transcriptional activity in HepG2 cells. HepG2NTCP cells were transduced with Ad-HBx and $24 \mathrm{~h}$ later the cells were probed for HBx and Smc6 expression by western blot, uncropped blots are available in Supplementary Fig. 6. In parallel experiments HepG2-NTCP cells were infected with $\mathrm{HBV}$ or a mutated virus lacking $\mathrm{HBx}\left(\mathrm{HBV}_{\mathrm{X}-}\right)$ (MOI of 200) in the presence or absence of Ad-HBx and the major viral transcript, pregenomic RNA measured at 6 days post-infection (a). HepG2-NTCP cells were transduced with Ad-HBx or Ad-OVA and HBx and HIF-1 $\alpha$ expression assessed at selected times after culturing at either $20 \%$ or $1 \%$ oxygen, uncropped blots are available in Supplementary Figs. 7 and 8 (b). Data is shown from a single experiment and is representative of three independent experiments where the mean data is presented. Statistical analysis was performed with Kruskal-Wallis test, with multiple comparisons adjusted by Dunn's correction.

in differentiated HepaRG-HBx ${ }_{\mathrm{WT}}$ cells (Fig. 2b). Thus we confirm that $\mathrm{HBx}$ in this model system is functionally active. As a control for these experiments we generated HepaRG cells encoding HBx with three nonsense mutations (HepaRG-HBx $\mathrm{X}_{\mathrm{STOP}}$ ). To assess whether $\mathrm{HBx}$ can promote or stabilize HIF expression we treated HepaRG$\mathrm{HBx}_{\mathrm{WT}}$ or HepaRG-HBx $\mathrm{X}_{\mathrm{STOP}}$ cells with Tet and cultured at $1 \%$ oxygen, a typical oxygen concentration used to model hypoxia ex vivo, or standard 'normoxic' laboratory conditions of $20 \%$ oxygen for $24 \mathrm{~h}$. HBx had minimal impact on HIF-1 1 or HIF-2a protein (Fig. 2c) or mRNA levels (Fig. 2d) in HepaRG cells cultured at 20\% oxygen. Culturing HepaRG-HBx ${ }_{\text {WT }}$ or HepaRG-HBx $\mathrm{STOp}_{\mathrm{S}}$ cells under $1 \%$ oxygen confirmed HIF-1 $\alpha$ or HIF-2 $\alpha$ expression and importantly showed a negligible effect of $\mathrm{HBx}$ on either HIF isoform (Fig. 2c). To assess whether HBx altered HIF transcriptional activity we quantified the mRNA levels of four HIF-regulated host genes (CAIX, BNIP3, VEGFA or GLUT1) (Fig. 2d) and CAIX protein expression (Fig. 2c) and observed no differences. Under normoxic conditions HIFs are hydroxylated by the oxygen-dependent PHDs and targeted for proteosomal degradation. Oxygen reperfusion of hypoxic cells results in a time-dependent loss of HIFs and we assessed whether the presence of HBx could alter the kinetics of HIF expression. A comparable decrease in HIF-1 $\alpha$ and HIF-2 $\alpha$ proteins was seen after 10-20 min of oxygen reperfusion in both Tet treated and untreated cells (Fig. 2e), demonstrating that $\mathrm{HBx}$ has a negligible effect on the kinetics of HIF degradation. In summary, we demonstrate that HepaRG cells are responsive to low oxygen and show a significant increase in hypoxia-associated gene transcription, this effect was not impacted by the co-expression of $\mathrm{HBx}$.

To further investigate a role for HBx to stabilize HIF-1 $\alpha$, we used an adenoviral vector engineered to express HBx (Ad-HBx) and showed HBx expression and Smc6 degradation. Transducing HepG2-NTCP cells with Ad-

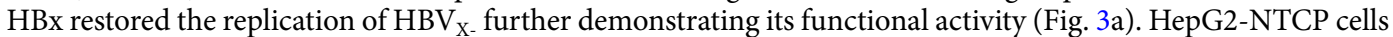
transduced with Ad-HBx or Ad-OVA (adenoviral vector expressing ovalbumin) were cultured at $20 \%$ or $1 \%$ oxygen and cells harvested over a $48 \mathrm{~h}$ period. We confirmed HBx expression $24 \mathrm{~h}$ post-transduction (Fig. 3b) and observed expression of HIF- $1 \alpha$ after $8 \mathrm{~h}$ at $1 \% \mathrm{O}_{2}$. Comparable expression levels of HIF-1a were noted in both Ad-HBx and Ad-OVA transduced cells, demonstrating a negligible effect of HBx on HIF-1a induction. These results further highlight a minimal role of $\mathrm{HBx}$ in regulating HIF- $1 \alpha$ or HIF- $2 \alpha$ mRNA or protein expression. 

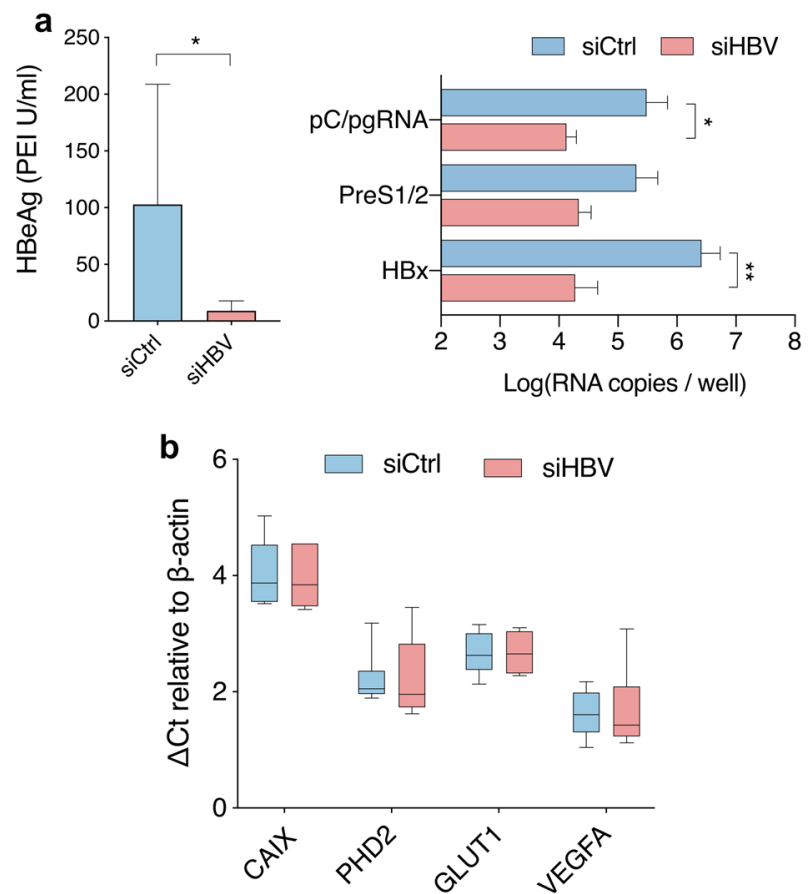

Figure 4. Effect of silencing viral transcription in HBV transgenic mice on hypoxia target gene transcripts. HBV transgenic mice ( $n=6$ per group) were treated with liver directed siRNAs targeting the HBx region (siHBV) which is commonly shared by all viral RNAs or with a control siRNA (siCtrl). Seven days later we assessed the efficacy of siHBV silencing by quantifying: serum HBeAg levels (a), HBV RNAs in the liver and hypoxia target gene (CAIX, VEGFA, GLUT1 and PHD2) RNAs (b). Hypoxia target genes values are expressed as $\triangle \mathrm{Ct}$ values by subtracting the $\mathrm{Ct}$ value of the housekeeping gene $\beta$-actin from $\mathrm{Ct}$ value of the gene of interest. Mann Whitney (a) or 2-way-ANOVA with Bonferroni correction (b) analyses were applied with $\mathrm{p}<0.05$ deemed as significant.

Studying HIF transcriptional activity in HBV transgenic mice. Since HBV can only infect humans and hominoid primates, no immune competent animal models are available that support natural HBV infection. One of the most-widely used murine models for studying $\mathrm{CHB}$ are transgenic mice expressing $\mathrm{HBV}$ from a single integrated genome (HBVtg). HBVtg mice have been reported to develop HCC that show similar chromosomal aberrations and gene expression patterns to human HBV-associated $\mathrm{HCC}^{53}$. To study the effect of HBV on HIF transcriptional activity in this model system, HBVtg mice were treated with lipid nanoparticle complexed, liver-targeted siRNAs designed to silence all HBV transcripts (siHBV $)^{54}$ or with an unspecific control siRNA (siCtrl). The HBV-specific siRNA led to effective HBV silencing with greater than 95\% reduction in $\mathrm{HBeAg}$ in the serum (Fig. 4a) and viral transcripts in the liver (Fig. 4b). However, silencing HBV mRNAs and antigens had no impact on HIF regulated gene transcripts (CAIX, VEGFA, GLUT1 and PHD2) (Fig. 4b). These studies suggest a minimal role of $\mathrm{HBV}$ encoded proteins or RNAs in promoting HIF transcriptional activity.

Studying HIF transcriptional activity in HBV infected hepatocytes and human liver chimeric mice. To complement the HBx studies described above we investigated the effect of HBV infection on HIF oxygen sensing pathways in current state-of-the-art in vitro and in vivo models. HepG2-NTCP cells were infected with HBV and cultured under normoxic conditions and sampled after 3 and 9 days to assess HIF-1 $\alpha$ or HIF-2 $\alpha$ expression. HBV gene expression was confirmed by measuring HBeAg $(53.96 \pm 2.7 \mathrm{IU} / \mathrm{mL})$ and $\mathrm{HBsAg}$ $(12.63 \pm 4.4 \mathrm{IU} / \mathrm{mL})$, however, we failed to detect either HIF or CAIX expression in the infected or non-infected cells (Fig. 5a). As a control we treated HepG2-NTCP cells with a HIF PHD inhibitor (FG4592 at $30 \mu \mathrm{M}$ ) and demonstrated HIF protein expression (Fig. 5a). Analyzing published RNA-seq data from HBV infected primary human hepatocytes ${ }^{55}$ showed no evidence of hypoxic gene upregulation (Fig. $5 \mathrm{~b}$ ). To further validate our conclusions we used the chimeric human liver FNRG mouse model ${ }^{56}$ to assess whether HBV infection would induce HIF signaling in this model. Female FNRG mice ${ }^{56}$ between $8-12$ weeks of age were transplanted with $0.5 \times 10^{6}$ cryopreserved adult human hepatocytes by intrasplenic injection and monitored for engraftment by measuring human albumin levels in the serum (at least $0.1 \mathrm{mg}$ human albumin per $\mathrm{mL}$ in peripheral blood). Engrafted animals were infected with 0.5 million genome equivalent (GE) copies of HBV per mouse and were monitored for $\mathrm{HBV}$ replication. Once stable viremia was established (minimum $5 \times 10^{7} \mathrm{GE} \mathrm{mL}^{-1}$ of serum) the mice were sacrificed and livers harvested from HBV infected $(n=4)$ and uninfected $(n=3)$ animals for RNA isolation and RNA-seq. Analyzing these RNA-seq data sets showed minimal evidence for an increase in hypoxic transcriptional activity in the HBV infected livers (Fig. 5b). For comparative purposes, we show that hypoxic genes were 

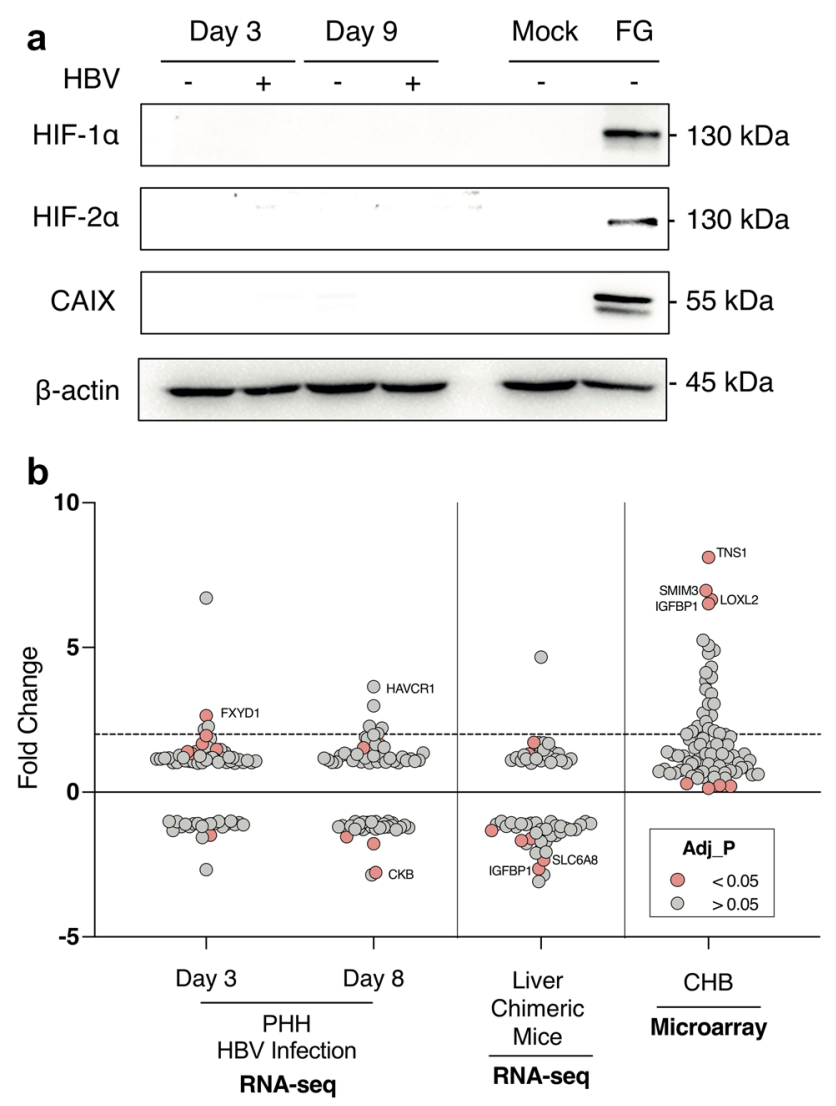

Figure 5. Comparing hypoxia gene signatures in HBV infected hepatocytes and humanized liver chimeric mice. Mock or HBV-infected HepG2-NTCP cells (MOI 200) were harvested after 3 or 9 days, lysed and assessed for HIF-1 $\alpha$, HIF- $2 \alpha$ or CAIX expression and the housekeeping gene B-actin by western blotting. As a positive control HepG2-NTCP cells were treated with the HIF PHD inhibitor FG4592 (FG, $30 \mu \mathrm{M}$ ) for $24 \mathrm{~h}$ and protein lysates analysed by western blotting, uncropped blots are available in Supplementary Fig. 9 (a). Induction of hypoxic genes (Supplementary Table 2) in transcriptomic data of HBV infected primary human hepatocytes ${ }^{55}$, HBV infected human liver chimeric mice and a CHB cohort (b). Fold change was calculated for each of the 80 genes in HBV infection against the healthy controls, where the dotted line represents a twofold change. For the $\mathrm{CHB}$ cohort, fold change was calculated from the raw Affymetrix, differential expression was tested using multiple $t$-tests and significance determined by (adjusted $p$ value $<0.05$ ).

upregulated in the $\mathrm{CHB}$ cohort ${ }^{41}$ (Fig. 5b), demonstrating the influence of inflammation on gene regulation and highlighting the limitations of current HBV replication models to model CHB.

\section{Discussion}

In this study we identified increased hypoxia gene signatures in a CHB cohort in the absence of cirrhosis or HCC. We confirmed hypoxic gene expression using MSigDB derived gene sets and recently reported signatures from HepG $2^{44}$ and PHH data sets ${ }^{45}$. We noted an increase in HIF-1a mRNA levels, consistent with their transcriptional regulation by inflammatory mediators such as TNFa. Given previous reports that HBx can stabilize HIFs ${ }^{32-40,57}$, we investigated whether functionally active $\mathrm{HBx}$ could regulate endogenous HIF- $1 \alpha$ and HIF- $2 \alpha$ mRNA, protein and transcriptional activity in vitro. We found minimal evidence for HBx regulation of HIFs in three independent model systems: an inducible HepaRG-HBx cell line; an Ad-HBx transduced cell, and in de novo infection of HepG2-NTCP or PHHs. Our study is distinct from earlier reports on at least three counts. Firstly, due to the technical difficulties in visualizing $\mathrm{HBx}$ by western blotting or immunofluorescent imaging, many of the earlier studies did not confirm HBx expression. Secondly, the majority of studies did not validate the functional activity of the expressed HBx protein. Finally, several studies assessed HBx stabilization of HIF-1 $\alpha$ using transient plasmid transfection systems with hypoxia reporter constructs, rather than directly measuring HIF expression and HIF target gene modulation. Given our current knowledge that HBx degrades Smc6 that silences episomal DNA transcription, the interpretation of these earlier plasmid based systems ${ }^{58}$ is now uncertain. Since we have directly confirmed expression and function of $\mathrm{HBx}$ in our in vitro models and quantified endogenous HIF transcriptional activity under normoxic or hypoxic conditions we are confident that HBx does not modulate HIF expression or transcriptional activity in the model systems used.

Guerrieri et al. identified and validated a role for HBx in regulating genes involved in endocytosis, predominantly members of the Ras-related in brain (Rab) family ${ }^{9}$. Anti-HBx chromatin immunoprecipitation studies 
identified $\mathrm{HBx}$ binding sites that included RAB1A, RAB2B and RAB5B promoters and none of the validated Rab genes were listed in our hypoxic gene set (Supplementary Table 2). Furthermore, GSEA of the CHB cohort or screening reactome gene sets showed only a modest enrichment in the 'Transferrin Endocytosis' pathway (Fig. 1e), suggesting a minimal overlap between HBx and HIF regulated genes.

Our results support a model where HBV infection associated inflammatory responses promote HIF expression and these complex virus-cell interactions are not recapitulated by simple in vitro culture systems, HBV transgenic mice or immunodeficient SCID human liver chimeric mouse models. This conclusion is supported by our observation of increased hypoxic gene expression in a cohort of HCV infected patients with cirrhosis (Fig. 1d). Analyzing the leading edge genes from the HBV $(n=30)$ and HCV $(n=23)$ cohorts identified 10 common genes, suggesting some gene specific differences between these chronic infections. Our bio-informatic analysis identified 25 hypoxia upregulated genes in chronic HBV infected patients, including LOXL2, SMIM3, TNS1, and IGFBP1. Notably, LOXL2 overexpression in HCC was previously associated with high tumour grade, metastasis, and poor patient overall and disease-free survival ${ }^{59}$. LOXL2 was shown to mediate its pathogenic effects in HCC angiogenesis via vasculogenic mimicry signalling, cytoskeleton reorganization, and bone-marrow derived cell recruitment ${ }^{59,60}$. In fact, hypoxia and HIF-1a signalling have been identified as key regulators of LOXL2 and driver of its pathogenesis, consistent with our observations ${ }^{60,61}$. Another significantly upregulated gene in chronic HBV patients, IGFBP1, was recently reported to be a HIF-2a regulated gene in vitro and in vivo model systems $^{62}$. Furthermore, IGFBP1 is a known NF- $\kappa$ B target gene and is induced by HBV infection ${ }^{63}$. These data suggest co-regulation of IGFBP1 by inflammatory pathways including NF- $\kappa \mathrm{B}$ and oxygen sensing mechanisms such as HIF signalling, which is consistent with our observation of inflammatory gene enrichment associating with hypoxia gene signature in $\mathrm{CHB}$.

Our observation of increased hypoxic gene signature expression in CHB patients offers an important insight into HBV disease stage stratification and suggest areas for bio-marker discovery for early HCC detection. This is in agreement with previous studies that have associated higher HIFa mRNA and protein expression in HCC with worse prognostic outcomes for HCC patients ${ }^{18-20}$. Moreover, as the liver is a naturally physiologically low oxygen environment, future investigations exploring how oxygen sensing pathways regulate HBV replication and pathogenesis may identify novel therapeutic targets.

\section{Materials and methods}

Cell lines and reagents. HepaRG cells expressing HBx under the control of a Tetracycline inducible promoter were cultured in Williams E medium supplemented with $10 \% \mathrm{FBS}, 50 \mathrm{IU}$ penicillin/streptomycin $\mathrm{mL}^{-1}$, $5 \mu \mathrm{g}$ human insulin $\mathrm{mL}^{-1}$ and $5 \times 10^{-7} \mathrm{M}$ hydrocortisone hemisuccinate (Sigma). As a control we generated HepaRG cells expressing an inactive $\mathrm{HBx}$ null mutant (HepaRG-HBx $\mathrm{x}_{\mathrm{STOP}}$ ) where three point nonsense mutations (relative to EcoRI site: C to A, 1393nt; C to A, 1396nt and C to T, 1397nt) were introduced to generate three stop codons (respectively, TGA, 1393nt; TGA, 1396nt; TAA, 1397nt) in HBV genotype D. HepG2-NTCP cells ${ }^{64}$ were maintained in Dulbecco's Modified Eagles Medium (DMEM) supplemented with $10 \%$ fetal bovine serum (FBS), 2 mM L-glutamine, $1 \mathrm{mM}$ Sodium Pyruvate, $50 \mathrm{IU}$ penicillin/streptomycin $\mathrm{mL}^{-1}$ and non-essential amino acids (Life Technologies, UK). HIF PHD inhibitor FG4592 was purchased from Cambridge Biosciences, UK. Cells were incubated under hypoxia in an atmosphere-regulated chamber with $1 \% \mathrm{O}_{2}: 5 \% \mathrm{CO}_{2}$ : balance $\mathrm{N}_{2}$ (Invivo 400, Baker-Ruskinn Technologies). The Ad-HBx and Ad-Ova express the HBV genotype D HBx gene and chicken ovalbumin gene under control of the Transthyretin (TTR) promoter. Promoter and insert were inserted into the E1 region of adenovirus (Ad5 $\Delta \mathrm{E} 1 / \mathrm{E} 3$ ) backbone plasmid pAd/PL-DEST through Gateway recombination following the manufacturer's instructions (Gateway System; Invitrogen, Karlsruhe, Germany). Adeno virus stocks were titrated using the cytopathic effect in HepG2 cells as previously described ${ }^{65}$.

HBV genesis and infection. HBV was purified from a HepAD38 producer line as previously reported ${ }^{64}$. Briefly, virus was purified using centrifugal filter devices (Centricon Plus-70 and Biomax 100.000, Millipore Corp., Bedford, MA) and stocks with a titre between $3 \times 10^{9}$ and $3 \times 10^{10}$ viral genome equivalents (vge) per $\mathrm{mL}$ stored at $-80^{\circ} \mathrm{C}$. HBV-X- virus was purified from a HepG2 based cell line containing a HBV $1.3 \times$ overlength integrated viral genome where both $5^{\prime}$ and $3^{\prime} \mathrm{HBx}$ genes were knocked out by a point mutation that changes the eight amino acid to a stop codon (CAA-to-TAA) as previously described ${ }^{51}$. HepG2-NTCP cells were treated with $2.5 \%$ dimethyl sulphoxide (DMSO) for 3 days and inoculated with HBV at an MOI of 200 in the presence of $4 \%$ polyethylene glycol 8,000. After 18-20 h the inoculum was removed by washing with PBS and the cells cultured in the presence of 2.5\% DMSO. Secreted HBe and HBs antigen were quantified by ELISA (Autobio, China).

SDS-PAGE and Western blotting. Samples were harvested using RIPA lysis buffer (20 mM Tris, $\mathrm{pH} 7.5$, $2 \mathrm{mM}$ EDTA, $150 \mathrm{mM} \mathrm{NaCl}, 1 \% \mathrm{NP} 40,1 \%$ sodium deoxycholate, and Roche protease inhibitor cocktail tablets). Lysed samples were mixed with $4 \times$ reducing buffer, and incubated at $95{ }^{\circ} \mathrm{C}$ for $5 \mathrm{~min}$. A $10 \%$ polyacrylamide gel was used for protein separation and transferred to PVDF membranes (Amersham). Membranes were cut at the $70 \mathrm{kDa}$ molecular weight mark, blocked in PBST, 5\% skimmed milk (Sigma), and incubated overnight with respective primary antibodies, as listed below. Blots were incubated in a 1:3,000 dilution of poly-clonal goat antimouse immunoglobulins/HRP (Dako (P0447) secondary antibody, before developing with Pierce SuperSignal West Pico chemiluminescent substrate kit. Images were captured with a ChemiDoc XRS + imaging system (BioRad). Where blots were sequentially probed for proteins of similar molecular weights, membranes were stripped in $0.5 \mathrm{M} \mathrm{NaOH}$ for $5 \mathrm{~min}$, before thorough washing with PBST, and blocking for $1 \mathrm{~h}$ in PBST 5\% skimmed milk before re-probing. The following primary antibodies were used at the listed dilutions in this study: HIF-1 $\alpha$, 1:1,000 (BD Biosciences: 610,959); anti-HIF-2a, 1:1,000 (Novus: NB100-132); anti- $\beta$-actin, 1:5,000 (Sigma: 
A5441); anti-SMC6, 1:1,000 (Abgent: AT3956a); anti-HBx, 1:500 (Abcam: AB39716); and anti-CAIX, 1:1,000 (Adrian Harris laboratory: University of Oxford).

PCR quantification of HBV RNA and HIF gene transcripts. Total cellular RNA was extracted using an RNeasy mini kit (Qiagen) following the manufacturer's instructions and samples treated with RNase-Free DNaseI (14 Kunitz units/rxn, Qiagen) for $30 \mathrm{~min}$ at room temperature. RNA concentration was measured by NanoDrop 1,000 spectrophotometer (Thermo Scientific) and cDNA synthesized with $0.25-1 \mu \mathrm{g}$ of RNA in a $20 \mu \mathrm{L}$ total reaction volume using a random hexamer/oligo dT strand synthesis kit in accordance with the manufacturer's instructions $\left(10 \mathrm{~min}\right.$ at $25^{\circ} \mathrm{C} ; 15 \mathrm{~min}$ at $42^{\circ} \mathrm{C} ; 15 \mathrm{~min}$ at $48^{\circ} \mathrm{C}$; SensiFast, Bioline). PCR amplification of HBV RNAs were performed using primers as previously described ${ }^{50}$ using a SYBR green real-time PCR proto$\mathrm{col}$ (qPCRBIO SyGreen, PCR Biosystems) in a Lightcycler $96^{\mathrm{Tx}}$ instrument (Roche). The amplification conditions were: $95^{\circ} \mathrm{C}$ for $2 \mathrm{~min}$ (enzyme activation), followed by 45 cycles of amplification $\left(95^{\circ} \mathrm{C}\right.$ for $5 \mathrm{~s} ; 60^{\circ} \mathrm{C}$ for $30 \mathrm{~s}$ ). HIF target genes were amplified using TaqMan ${ }^{\star}$ Gene Expression assays (CAIX [Hs00154208_m1]; VEGFA [Hs00900055_m1]; BNIP3 [Hs00969291_m1] and GLUT1 [Hs00892681_m1]) (Thermo Fisher) and amplified using a Taqman real-time PCR protocol (qPCRBIO probe, PCR Biosystems) using the same conditions as listed above.

HBV transgenic mice and siRNA delivery. Animal experiments were conducted in accordance with the German regulations of the Society for Laboratory Animal Science (GV-SOLAS) and the European Health Law of the Federation of Laboratory Animal Science Associations (FELASA). Experiments were approved by the local Animal Care and Use Committee of Upper Bavaria and followed the 3R rules. Mice were kept in a specific-pathogen-free facility under appropriate biosafety level following institutional guidelines. HBVtg mice (strain HBV1.3.32) 66,67 carrying a 1.3-fold overlength HBV genome (genotype D) on a C57BL/6J background and both male and female mice between 12-15 weeks were used. The HBV specific siRNA (siHBV) was designed to silence all HBV transcripts by targeting the 3 ' region of the HBV genome and the control siRNA (siCtrl) does not target any viral or known host transcripts. siRNAs were complexed with Invivofectamine 3.0 reagent (ThermoFisher Scientific) before injecting $1 \mu \mathrm{g} / \mathrm{g}$ body weight into the tail vain. HBeAg was quantified from mouse sera after dilution with the Architect HBsAg Manual Diluent using the quantitative HBeAg Reagent Kit (Ref: 6C32-27) with HBeAg Quantitative Calibrators (Ref.: 7P24-01) on an Architect TM platform (Abbott Laboratories, Wiesbaden, Germany). Immediately after sacrificing the mice and preparation of the liver, an approximately $0.4 \mathrm{~mm}$ thick and 1-1.5 cm long peace of liver was placed in $500 \mu \mathrm{L}$ RNAlater. After storage for $24 \mathrm{~h}$ at $4{ }^{\circ} \mathrm{C}$ (to allow RNA later to penetrate tissue) the tissue was transferred to $-20^{\circ} \mathrm{C}$ and stored until RNA preparation. RNA was prepared using the RNeasy Mini kit (Qiagen), where an approximate $20 \mathrm{mg}$ piece of frozen liver was placed in a $2 \mathrm{~mL}$ micro-centrifuge tube pre-cooled on dry ice. After adding $600 \mu \mathrm{L}$ of Buffer RLT, tissue was homogenized using the TissueLyser LT (Qiagen) for $5 \mathrm{~min}$ at $50 \mathrm{~Hz}$. Total RNA was extracted following the protocol of the RNeasy mini kit.

HBV infected human chimeric mice and RNA-sequencing. Mock and HBV infected mice were sacrificed and livers harvested for RNA isolation and RNA-sequencing at the Beijing Genomics Institute (BGI, Hong Kong). RNA purity was assessed with a NanoDrop 2000 spectrophotometer (Thermo Fisher Scientific) and integrity determined using a 2100 Bioanalyzer Instrument (Agilent Technologies). Sequencing was performed on a BGISEQ-500 (Beijing Genomics Institute, Hong Kong) employing the PE100 mode to produce raw paired-end reads of $100 \mathrm{bp}$ and SOAPnuke (v1.5.2) software to filter out non-human sequencing reads, as previously reported ${ }^{57,68,69}$. Clean reads (FASTQ files) were uploaded to Partek Flow (version 8.0, build 8.0.19.1125; Partek Inc., St. Louis, MO, USA), quality-controlled, and aligned to the human genome (hg38) with STAR-2.6.1d aligner software. Genes were quantified using the transcript model Ensembl Transcripts release 91 and differential expression determined with DESeq2 (3.5). Microarray analysis was performed with Partek Genomics Suite (v6.6) as previously described ${ }^{70}$. Scatter dot plots of fold change values were plotted with Graphpad Prism version 8. RNA-seq data are deposited in the GEO archive at NCBI, with the accession number GSE145835 and entitled: Transcriptional profiling of hepatocytes isolated from chronically HBV-infected human liver chimeric mice.

Gene set enrichment analysis. GSEA was performed with GSEA_4.0.3 $3^{71}$ using publicly available Affymetrix microarray datasets ${ }^{41,49}$ from Gene Expression Omnibus (GEO) (accessions: GSE83148, GSE14323). Gene sets were derived from HepG2 RNA-seq data ${ }^{44}$ downloaded from GEO (GSE120886) or PHH RNA-Seq accessed from the published Supplementary Material ${ }^{45}$. To determine whether HBV infection induces hypoxia-responsive genes, we interrogated the mRNA expression patterns of the liver chimeric mice RNA-Seq dataset for the top 80 hypoxia-induced genes as identified in HepG2 hepatic cells ${ }^{44}$. In-house datasets were compared with RNAseq $^{55}$ from HBV-infected primary human hepatocytes. Data were retrieved from GEO (accessions: GSE120886, GSE93153, GSE118295). For consistency, all datasets were re-analysed with the same Partek Flow bioinformatic pipeline. Microarray analysis was performed with Partek Genomics Suite (v6.6) as previously described ${ }^{70}$ and data presented using Graphpad Prism 8.

Statistical analyses. All analyses were performed using Prism 8 (GraphPad, La Jolla, CA). Data are shown as means $\pm \mathrm{SD}$, probabilities are indicated by ${ }^{\star} \mathrm{p}<0.05,{ }^{* *} \mathrm{p}<0.01,{ }^{* * *} \mathrm{p}<0.001$ or ${ }^{* * *} \mathrm{p}<0.0001$, with Bonferroni corrections for multiple testing when appropriate. 


\section{Data availability}

RNA-seq data from HBV infected mice are deposited in the GEO archive at NCBI, with the accession number GSE145835 and entitled: Transcriptional profiling of hepatocytes isolated from chronically HBV-infected human liver chimeric mice. Our in-house data was compared with RNA-seq ${ }^{55}$ from HBV-infected primary human hepatocytes and data retrieved from GEO (accessions: GSE120886, GSE93153, GSE118295).

Received: 27 March 2020; Accepted: 31 July 2020

Published online: 24 August 2020

\section{References}

1. Sugarman, J. et al. Ethics and hepatitis B cure research. Gut 66, 389-392. https://doi.org/10.1136/gutjnl-2016-313009 (2017).

2. World Health Organization. Global Hepatitis Report 2017 (World Health Organization, Geneva, 2017).

3. Nassal, M. HBV cccDNA: viral persistence reservoir and key obstacle for a cure of chronic hepatitis B. Gut 64, 1972-1984. https ://doi.org/10.1136/gutjnl-2015-309809 (2015).

4. Grossi, G., Vigano, M., Loglio, A. \& Lampertico, P. Hepatitis B virus long-term impact of antiviral therapy nucleot(s)ide analogues (NUCs). Liver Int. 37(Suppl 1), 45-51. https://doi.org/10.1111/liv.13291 (2017).

5. Bray, F. et al. Global cancer statistics 2018: GLOBOCAN estimates of incidence and mortality worldwide for 36 cancers in 185 countries. CA Cancer J. Clin. 68, 394-424. https://doi.org/10.3322/caac.21492 (2018).

6. European Asscoiation for the Study of the Liver. L. EASL clinical practice guidelines: management of hepatocellular carcinoma. J. Hepatol. 69, 182-236. https://doi.org/10.1016/j.jhep.2018.03.019 (2018).

7. Ringelhan, M., McKeating, J. A. \& Protzer, U. Viral hepatitis and liver cancer. Philos. Trans. R. Soc. Lond. B https://doi.org/10.1098/ rstb.2016.0274 (2017).

8. Levrero, M. \& Zucman-Rossi, J. Mechanisms of HBV-induced hepatocellular carcinoma. J. Hepatol. 64, S84-S101. https://doi. org/10.1016/j.jhep.2016.02.021 (2016).

9. Guerrieri, F. et al. Genome-wide identification of direct HBx genomic targets. BMC Genom. 18, 184. https://doi.org/10.1186/s1286 4-017-3561-5 (2017).

10. Rappaport, A. M. The structural and functional unit in the human liver (liver acinus). Anat. Rec. 130, 673-689. https://doi. org/10.1002/ar.1091300405 (1958).

11. Braeuning, A. et al. Differential gene expression in periportal and perivenous mouse hepatocytes. FEBS J. 273, 5051-5061. https ://doi.org/10.1111/j.1742-4658.2006.05503.x (2006).

12. Jungermann, K. \& Kietzmann, T. Zonation of parenchymal and nonparenchymal metabolism in liver. Annu. Rev. Nutr. 16, 179-203. https://doi.org/10.1146/annurev.nu.16.070196.001143 (1996).

13. Halpern, K. B. et al. Single-cell spatial reconstruction reveals global division of labour in the mammalian liver. Nature 542, 352-356. https://doi.org/10.1038/nature21065 (2017).

14. Wilson, G. K., Tennant, D. A. \& McKeating, J. A. Hypoxia inducible factors in liver disease and hepatocellular carcinoma: current understanding and future directions. J. Hepatol. 61, 1397-1406. https://doi.org/10.1016/j.jhep.2014.08.025 (2014).

15. Pugh, C. W. \& Ratcliffe, P. J. New horizons in hypoxia signaling pathways. Exp. Cell Res. 356, 116-121. https://doi.org/10.1016/j. yexcr.2017.03.008 (2017)

16. Ratcliffe, P. J. Oxygen sensing and hypoxia signalling pathways in animals: the implications of physiology for cancer. J. Physiol. 591, 2027-2042. https://doi.org/10.1113/jphysiol.2013.251470 (2013).

17. Scholz, C. C. \& Taylor, C. T. Targeting the HIF pathway in inflammation and immunity. Curr. Opin. Pharmacol. 13, 646-653. https ://doi.org/10.1016/j.coph.2013.04.009 (2013).

18. Dai, C. X. et al. Hypoxia-inducible factor-1 alpha, in association with inflammation, angiogenesis and MYC, is a critical prognostic factor in patients with HCC after surgery. BMC Cancer 9, 418. https://doi.org/10.1186/1471-2407-9-418 (2009).

19. Xiang, Z. L. et al. Gene expression profiling of fixed tissues identified hypoxia-inducible factor-1alpha, VEGF, and matrix metalloproteinase-2 as biomarkers of lymph node metastasis in hepatocellular carcinoma. Clin. Cancer Res. 17, 5463-5472. https://doi. org/10.1158/1078-0432.CCR-10-3096 (2011).

20. Zheng, S. S., Chen, X. H., Yin, X. \& Zhang, B. H. Prognostic significance of HIF-1alpha expression in hepatocellular carcinoma: a meta-analysis. PLoS ONE 8, e65753. https://doi.org/10.1371/journal.pone.0065753 (2013).

21. Rius, J. et al. NF-kappaB links innate immunity to the hypoxic response through transcriptional regulation of HIF-1alpha. Nature 453, 807-811. https://doi.org/10.1038/nature06905 (2008).

22. Palazon, A., Goldrath, A. W., Nizet, V. \& Johnson, R. S. HIF transcription factors, inflammation, and immunity. Immunity 41, 518-528. https://doi.org/10.1016/j.immuni.2014.09.008 (2014).

23. Masson, N. et al. The FIH hydroxylase is a cellular peroxide sensor that modulates HIF transcriptional activity. EMBO Rep. 13, 251-257. https://doi.org/10.1038/embor.2012.9 (2012).

24. Bonello, S. et al. Reactive oxygen species activate the HIF-1alpha promoter via a functional NFkappaB site. Arterioscler. Thromb. Vasc. Biol. 27, 755-761. https://doi.org/10.1161/01.ATV.0000258979.92828.bc (2007).

25. Garcia, M. A. et al. Activation of NF-kB pathway by virus infection requires Rb expression. PLoS ONE 4, e6422. https://doi. org/10.1371/journal.pone.0006422 (2009).

26. Wilson, G. K. et al. A dual role for hypoxia inducible factor-1alpha in the hepatitis C virus lifecycle and hepatoma migration. J. Hepatol. 56, 803-809. https://doi.org/10.1016/j.jhep.2011.11.018 (2012).

27. Ripoli, M. et al. Hepatitis C virus-linked mitochondrial dysfunction promotes hypoxia-inducible factor 1 alpha-mediated glycolytic adaptation. J. Virol. 84, 647-660. https://doi.org/10.1128/JVI.00769-09 (2010).

28. Nasimuzzaman, M., Waris, G., Mikolon, D., Stupack, D. G. \& Siddiqui, A. Hepatitis C virus stabilizes hypoxia-inducible factor 1alpha and stimulates the synthesis of vascular endothelial growth factor. J. Virol. 81, 10249-10257. https://doi.org/10.1128/ JVI.00763-07 (2007).

29. Nakamura, M. et al. Hypoxia-specific stabilization of HIF-1alpha by human papillomaviruses. Virology 387, 442-448. https://doi. org/10.1016/j.virol.2009.02.036 (2009).

30. Shin, Y. C., Joo, C. H., Gack, M. U., Lee, H. R. \& Jung, J. U. Kaposi's sarcoma-associated herpesvirus viral IFN regulatory factor 3 stabilizes hypoxia-inducible factor-1 alpha to induce vascular endothelial growth factor expression. Cancer Res. 68, 1751-1759. https://doi.org/10.1158/0008-5472.CAN-07-2766 (2008).

31. McFarlane, S., Nicholl, M. J., Sutherland, J. S. \& Preston, C. M. Interaction of the human cytomegalovirus particle with the host cell induces hypoxia-inducible factor 1 alpha. Virology 414, 83-90. https://doi.org/10.1016/j.virol.2011.03.005 (2011).

32. Yoo, Y. G. et al. Hepatitis B virus X protein enhances transcriptional activity of hypoxia-inducible factor-1alpha through activation of mitogen-activated protein kinase pathway. J. Biol. Chem. 278, 39076-39084. https://doi.org/10.1074/jbc.M305101200 (2003).

33. Moon, E. J. et al. Hepatitis B virus X protein induces angiogenesis by stabilizing hypoxia-inducible factor-1alpha. FASEB J. 18, 382-384. https://doi.org/10.1096/fj.03-0153fje (2004). 
34. Yoo, Y. G., Cho, S., Park, S. \& Lee, M. O. The carboxy-terminus of the hepatitis B virus X protein is necessary and sufficient for the activation of hypoxia-inducible factor-1alpha. FEBS Lett. 577, 121-126. https://doi.org/10.1016/j.febslet.2004.10.004 (2004).

35. Han, H. K., Han, C. Y., Cheon, E. P., Lee, J. \& Kang, K. W. Role of hypoxia-inducible factor-alpha in hepatitis-B-virus X proteinmediated MDR1 activation. Biochem. Biophys. Res. Commun. 357, 567-573. https://doi.org/10.1016/j.bbrc.2007.04.012 (2007).

36. Xie, H. et al. The expression of hypoxia-inducible factor-1alpha in hepatitis B virus-related hepatocellular carcinoma: correlation with patients' prognosis and hepatitis B virus X protein. Dig. Dis. Sci. 53, 3225-3233. https://doi.org/10.1007/s10620-008-0296-9 (2008).

37. Yoo, Y. G. et al. Hepatitis B virus X protein induces the expression of MTA1 and HDAC1, which enhances hypoxia signaling in hepatocellular carcinoma cells. Oncogene 27, 3405-3413. https://doi.org/10.1038/sj.onc.1211000 (2008).

38. Holotnakova, T. et al. Role of the HBx oncoprotein in carbonic anhydrase 9 induction. J. Med. Virol. 82, 32-40. https://doi. org/10.1002/jmv.21671 (2010)

39. Liu, L. P. et al. HBx mutants differentially affect the activation of hypoxia-inducible factor-1alpha in hepatocellular carcinoma. $B r$. J. Cancer 110, 1066-1073. https://doi.org/10.1038/bjc.2013.787 (2014).

40. Zhu, M. et al. Hepatitis B virus X protein induces expression of alpha-fetoprotein and activates PI3K/mTOR signaling pathway in liver cells. Oncotarget 6, 12196-12208. https://doi.org/10.18632/oncotarget.2906 (2015).

41. Zhou, W. et al. Predictive model for inflammation grades of chronic hepatitis B: large-scale analysis of clinical parameters and gene expressions. Liver Int. 37, 1632-1641. https://doi.org/10.1111/liv.13427 (2017).

42. Liberzon, A. et al. The molecular signatures database (MSigDB) hallmark gene set collection. Cell Syst. 1, 417-425. https://doi. org/10.1016/j.cels.2015.12.004 (2015).

43. Schodel, J. et al. High-resolution genome-wide mapping of HIF-binding sites by ChIP-seq. Blood 117, e207-217. https://doi. org/10.1182/blood-2010-10-314427 (2011).

44. Smythies, J. A. et al. Inherent DNA-binding specificities of the HIF-1alpha and HIF-2alpha transcription factors in chromatin. EMBO Rep. https://doi.org/10.15252/embr.201846401 (2019).

45. Hettiarachchi, G. K. et al. Translational and transcriptional responses in human primary hepatocytes under hypoxia. Am. J. Physiol. Gastrointest. Liver Physiol. 316, G720-G734. https://doi.org/10.1152/ajpgi.00331.2018 (2019).

46. Elaut, G. et al. Molecular mechanisms underlying the dedifferentiation process of isolated hepatocytes and their cultures. Curr. Drug Metab. 7, 629-660. https://doi.org/10.2174/138920006778017759 (2006).

47. Heslop, J. A. et al. Mechanistic evaluation of primary human hepatocyte culture using global proteomic analysis reveals a selective dedifferentiation profile. Arch. Toxicol. 91, 439-452. https://doi.org/10.1007/s00204-016-1694-y (2017).

48. Chang, M. L. \& Liaw, Y. F. Hepatitis B flares in chronic hepatitis B: pathogenesis, natural course, and management. J. Hepatol. 61, 1407-1417. https://doi.org/10.1016/j.jhep.2014.08.033 (2014).

49. Mas, V. R. et al. Genes involved in viral carcinogenesis and tumor initiation in hepatitis $C$ virus-induced hepatocellular carcinoma. Mol. Med. 15, 85-94. https://doi.org/10.2119/molmed.2008.00110 (2009).

50. D'Arienzo, V. et al. A PCR assay to quantify patterns of HBV transcription. J. Gen. Virol. https://doi.org/10.1099/jgv.0.001373 (2019).

51. Lucifora, J. et al. Hepatitis B virus X protein is essential to initiate and maintain virus replication after infection. J. Hepatol. 55, 996-1003. https://doi.org/10.1016/j.jhep.2011.02.015 (2011).

52. Decorsiere, A. et al. Hepatitis B virus X protein identifies the Smc5/6 complex as a host restriction factor. Nature 531, 386-389. https://doi.org/10.1038/nature17170 (2016).

53. Ringelhan, M. \& Protzer, U. Oncogenic potential of hepatitis B virus encoded proteins. Curr. Opini. Virol. 14, 109-115. https:// doi.org/10.1016/j.coviro.2015.08.015 (2015).

54. Michler, T. et al. Knockdown of virus antigen expression increases therapeutic vaccine efficacy in high-titer HBV carrier mice. Gastroenterology https://doi.org/10.1053/j.gastro.2020.01.032 (2020).

55. Niu, C. et al. The Smc5/6 complex restricts HBV when localized to ND10 without inducing an innate immune response and is counteracted by the HBV X protein shortly after infection. PLoS ONE 12, e0169648. https://doi.org/10.1371/journal.pone.01696 48 (2017).

56. Wilson, E. M. et al. Extensive double humanization of both liver and hematopoiesis in FRGN mice. Stem Cell Res. 13, 404-412. https://doi.org/10.1016/j.scr.2014.08.006 (2014).

57. Fehlmann, T. et al. cPAS-based sequencing on the BGISEQ-500 to explore small non-coding RNAs. Clin. Epigenetics 8, 123. https ://doi.org/10.1186/s13148-016-0287-1 (2016).

58. van Breugel, P. C. et al. Hepatitis B virus X protein stimulates gene expression selectively from extrachromosomal DNA templates. Hepatology 56, 2116-2124. https://doi.org/10.1002/hep.25928 (2012).

59. Shao, B. et al. LOXL2 promotes vasculogenic mimicry and tumour aggressiveness in hepatocellular carcinoma. J. Cell Mol. Med. 23, 1363-1374. https://doi.org/10.1111/jcmm.14039 (2019).

60. Wong, C. C. et al. Lysyl oxidase-like 2 is critical to tumor microenvironment and metastatic niche formation in hepatocellular carcinoma. Hepatology 60, 1645-1658. https://doi.org/10.1002/hep.27320 (2014).

61. Wang, M. et al. HIF-1alpha promoted vasculogenic mimicry formation in hepatocellular carcinoma through LOXL2 up-regulation in hypoxic tumor microenvironment. J. Exp. Clin. Cancer Res. 36, 60. https://doi.org/10.1186/s13046-017-0533-1 (2017).

62. Geis, T. et al. HIF-2alpha attenuates lymphangiogenesis by up-regulating IGFBP1 in hepatocellular carcinoma. Biol. Cell 107, 175-188. https://doi.org/10.1111/boc.201400079 (2015).

63. Wu, S. et al. Cooperative effects of hepatitis B virus and TNF may play important roles in the activation of metabolic pathways through the activation of NF-kappaB. Int. J. Mol. Med. 38, 475-481. https://doi.org/10.3892/ijmm.2016.2643 (2016).

64. Ko, C. et al. Hepatitis B virus genome recycling and de novo secondary infection events maintain stable cccDNA levels. J. Hepatol. 69, 1231-1241. https://doi.org/10.1016/j.jhep.2018.08.012 (2018).

65. Sprinzl, M. F., Oberwinkler, H., Schaller, H. \& Protzer, U. Transfer of hepatitis B virus genome by adenovirus vectors into cultured cells and mice: crossing the species barrier. J. Virol. 75, 5108-5118. https://doi.org/10.1128/JVI.75.11.5108-5118.2001 (2001).

66. Guidotti, L. G., Matzke, B., Schaller, H. \& Chisari, F. V. High-level hepatitis B virus replication in transgenic mice. J. Virol. 69, 6158-6169 (1995).

67. Michler, T. et al. Blocking sense-strand activity improves potency, safety and specificity of anti-hepatitis B virus short hairpin RNA. EMBO Mol. Med. 8, 1082-1098. https://doi.org/10.15252/emmm.201506172 (2016).

68. Huang, J. et al. A reference human genome dataset of the BGISEQ-500 sequencer. Gigascience 6, 1-9. https://doi.org/10.1093/gigas cience/gix024 (2017)

69. Mak, S. S. T. et al. Comparative performance of the BGISEQ-500 vs Illumina HiSeq2500 sequencing platforms for palaeogenomic sequencing. Gigascience 6, 1-13. https://doi.org/10.1093/gigascience/gix049 (2017).

70. Giotis, E. S. et al. Constitutively elevated levels of SOCS1 suppress innate responses in DF-1 immortalised chicken fibroblast cells. Sci. Rep. 7, 17485. https://doi.org/10.1038/s41598-017-17730-2 (2017).

71. Subramanian, A., Kuehn, H., Gould, J., Tamayo, P. \& Mesirov, J. P. GSEA-P: a desktop application for gene set enrichment analysis. Bioinformatics 23, 3251-3253. https://doi.org/10.1093/bioinformatics/btm369 (2007). 


\section{Acknowledgements}

We thank Peter Ratcliffe for his support and advice throughout this project and Massimo Levrero for helpful discussions and invaluable insights on HBx. We thank Peter Balfe for critical reading of the manuscript. Research in the McKeating laboratory is funded by Wellcome Trust IA 200838/Z/16/Z and MRC project Grant MR/ R022011/1. Collaborative research in the Protzer and McKeating laboratories was funded by EU Horizon 2020 program through the Hep-CAR consortium and the Institute for Advanced Study with the support of the Technische Universität München via the German Excellence Initiative and EU 7th Framework Programme under grant agreement number 291763. TM was supported by a clinical leave stipend by the Else-Kröner Forschungskolleg "Microbial triggers as cause for disease" of Klinikum rechts der Isar, Technische Universität München. Research in the Klenerman lab is funded by Wellcome grant WT 109965MA and NIHR senior Fellowship. Research in Dorner laboratory was funded by an ERC grant (ERC-StG-2015-637304) and Wellcome Trust New Investigator award $(104771 / \mathrm{Z} / 14 / \mathrm{Z})$.

\section{Author contributions}

P.J.L. designed and conducted experiments and co-wrote the manuscript; J.M.H. designed and conducted experiments and co-wrote the manuscript; E.M. analysed data; V.D. conducted experiments; T.M. designed and conducted experiments and co-wrote the manuscript; P.A.C.W. conducted experiments; A.M. analysed data; A.M.O.-P. conducted experiments; M.vd.K. provided reagents, J.W. provided reagents; D.D. provided reagents; M.D. designed experiments; P.K. provided expertise; U.P. provided reagents; S.G. analyzed data and co-wrote the manuscript and JAM designed the study and co-wrote the manuscript.

\section{Competing interests}

The authors declare no competing interests.

\section{Additional information}

Supplementary information is available for this paper at https://doi.org/10.1038/s41598-020-70865-7.

Correspondence and requests for materials should be addressed to J.A.M.

Reprints and permissions information is available at www.nature.com/reprints.

Publisher's note Springer Nature remains neutral with regard to jurisdictional claims in published maps and institutional affiliations.

(c) Open Access This article is licensed under a Creative Commons Attribution 4.0 International License, which permits use, sharing, adaptation, distribution and reproduction in any medium or format, as long as you give appropriate credit to the original author(s) and the source, provide a link to the Creative Commons licence, and indicate if changes were made. The images or other third party material in this article are included in the article's Creative Commons licence, unless indicated otherwise in a credit line to the material. If material is not included in the article's Creative Commons licence and your intended use is not permitted by statutory regulation or exceeds the permitted use, you will need to obtain permission directly from the copyright holder. To view a copy of this licence, visit http://creativecommons.org/licenses/by/4.0/.

(C) The Author(s) 2020 